\title{
Compósitos poliméricos reforçados com fibras naturais da Amazônia fabricados por infusão
}

\author{
Polimeric composites reinforced with \\ natural fibers from Amazon \\ manufactured by infusion
}

\author{
Jean Rodrigues ${ }^{1}$, José Antônio Souza ${ }^{1}$, \\ Roberto Fujiyama ${ }^{2}$
}

\author{
${ }^{1}$ Programa de Pós-Graduação em Engenharia de Recursos Naturais da Amazônia - PRODERNA/ITEC/UFPA CEP: \\ 66075-110, Belém, PA \\ e-mail: jean.rodrigues@ifpa.edu.br; jass@ufpa.br \\ ${ }^{2}$ Programa de Pós-Graduação em Engenharia Mecânica - PPGEM/ITEC/UFPA CEP: 66075-110, Belém, PA \\ e-mail: fujiyama@ufpa.br
}

\section{RESUMO}

O desenvolvimento de compósitos reforçados com fibras naturais se alia à nova lógica do desenvolvimento sustentável e potencializa a produção de materiais ambientalmente corretos. A chave para tornar economicamente viável e ambientalmente favoráveis estes novos materiais passa pela adaptação de técnicas consagradas de fabricação de compósitos às propriedades peculiares e intrínsecas das fibras naturais, como o processo de infusão, que por se tratar de um processamento em molde fechado contribui para a redução das emissões de voláteis ao meio ambiente na etapa de fabricação. Neste trabalho estudaram-se como as principais variáveis do processo de infusão afetam as propriedades do compósito quando são utilizadas fibras naturais como reforço de uma matriz de poliéster insaturado. Produziram-se placas reforçadas com fibras de curauá, juta e palha da costa arranjadas na forma de fios alinhados ou tecido em estilo plano sob diferentes níveis de vácuo no processamento. A elevação do nível de vácuo altera a condição de compactação das fibras modificando sua porosidade, interface fibra/matriz e consequentemente as propriedades do compósito. Os compósitos foram caracterizados quanto à sua resistência à tração, módulo de elasticidade, impacto Charpy e porosidade. Os resultados mostraram que o processo de infusão possibilitou a fabricação de compósitos com até $45 \%$ de fração volumétrica de fibra, com porosidade em torno de $2 \%$ e excelente estabilidade dimensional. Verificouse ainda que, no geral, a elevação do nível de vácuo alterou significativamente as condições de compactação dos reforços, alterando, a depender da estrutura da fibra utilizada, a eficiência da interface matriz/reforço.

Palavras-chave: infusão, curauá, juta, palha da costa.

\section{ABSTRACT}

The development of composites reinforced with natural fibers is allied to the new logic of sustainable development and enhances the production of environmentally friendly materials. The key to making economically viable and environmentally friendly these new materials involves the adaptation of standard techniques of composites manufacturing to the peculiar and intrinsic properties of natural fibers, such as the infusion process which in function to be a closed mold processing helps reduce of volatile emission to the environment at the fabrication stage. In this work we have been studied as the primary variables of the infusion process affect the properties of the composite when natural fibers are used as reinforcing an unsaturated polyester matrix. They were produced plates reinforced with curaua fibers, jute and raffia arranged in form of aligned fibers or fabric in plain style under different vacuum levels in processing. The increase in the vacuum level changes the fiber compaction condition modifying its porosity, fiber / matrix interface and consequently composite properties. The composites were characterized for its tensile strength, elastic modulus, Charpy impact and porosity. The results showed that the infusion process enabled the manufacture of composites with up to $45 \%$ volume fraction of fiber, porosity about $2 \%$ and excellent dimensional stability. It was also 
found that, in general, raising the vacuum level significantly alter the compression ribs conditions changing, depending on the fiber structure used, the efficiency of the interface matrix / reinforcement.

Keywords: Infusion, curaua, jute, raffia.

\section{INTRODUÇÃO}

O desenvolvimento tecnológico relacionado com as exigências de consumo continua a aumentar a demanda sobre os recursos globais, levando a grandes questões de disponibilidade de material e sustentabilidade ambiental [1]. Neste cenário, diversos setores têm buscado alternativas no sentido de mitigar os impactos ambientais decorrentes dos processos produtivos, bem como do uso dos produtos fabricados e seu descarte.

Nos últimos anos, regulamentações governamentais sobre as emissões de dióxido de carbono e capacidade de reciclagem dos materiais têm produzido um aumento na utilização de materiais compósitos de fibras naturais, tanto nas indústrias automotivas e da construção. Mas uma das chaves do seu sucesso é a possibilidade de uso de técnicas de processamento de compósitos de fibra de vidro bem estudadas, como RTM, VARTM ou SCRIMP. Portanto, é crucial para entender como as principais variáveis de processamento são afetadas quando as fibras de vidro são substituídas por fibras naturais, que têm estrutura diferente, arquitetura de tecido diferente e interações químicas diferentes com as resinas. Uma dessas variáveis é a permeabilidade do tecido, que é o parâmetro chave que regula o fluxo no leito de fibras, juntamente com a viscosidade do fluido. A permeabilidade dos tecidos é especialmente importante nas técnicas de injeção de baixa pressão, como VARTM ou infusão a vácuo (Vacuum Infusion Process - VIP), onde a formação de vazios e o tempo de injeção podem ser aumentados dramaticamente quando a permeabilidade diminui [2].

O processo de infusão a vácuo (VIP) é um processo de moldagem utilizado para a fabricação de grandes estruturas compósitas. A sua popularidade se deve em parte ao baixo custo do conjunto de ferramental e a segurança ambiental (o processo elimina mais do que 90\% dos compostos orgânicos voláteis emitidos por resinas de poliéster insaturadas). Além disso, o baixo envolvimento do operador aumenta a reprodutibilidade do processo em comparação com as técnicas de molde aberto como hand-lay-up ou spray-up e os componentes são de relativamente alto teor de fibras, de até $60 \%$ em volume [3].

Compósitos reforçados com biofibras (biofiber composites) têm sido submetidos a uma transformação extraordinária. Estes materiais têm se tornado mais e mais suficientes à medida que novas composições e processos têm sido intensamente pesquisados, desenvolvidos e consequentemente aplicados. A crise do petróleo fez os biocompósitos significativamente importantes e estes têm se tornado materiais de engenharia com uma gama muito ampla de propriedades. No entanto, como todos os materiais, eles estão constantemente sob a pressão competitiva do mercado global, que por sua vez, exige um desenvolvimento contínuo [1].

Neste trabalho produziu-se utilizando a técnica de infusão de resina, compósitos de matriz de poliéster insaturado reforçados com fibras de curuá, juta e palha da costa, dispostos na forma de tecidos em estilo plano e fios alinhados. Objetivando-se investigar as variáveis do processo de fabricação e o estado de compactação das fibras em função de sua disposição e geometria, os compósitos foram produzidos sobre dois diferentes níveis de vácuo com fibras dispostas na forma de fios alinhados e tecidos em estilo plano.

\section{MATERIAIS E MÉTODOS}

O polímero utilizado no trabalho foi o poliéster insaturado ortoftálico de baixa reatividade, cristal, viscosidade de 0,48 Pa.s, fabricado pela Embrapol sobre a denominação comercial ALPHA 190. O agente de cura utilizado foi o peróxido de MEK na proporção de 0,33 \% (v/v). As fibras naturais utilizadas foram as fibras de curauá (Ananas erectifolius), juta (Corchorus capsularis) e palha da costa (Raphia vinífera).

As fibras de curauá foram fornecidas pela EMBRAPA da Amazônia Oriental e foram utilizadas na forma de fibras alinhadas e tecidos em estilo plano (tela), com gramatura média de $0,035 \mathrm{~g} / \mathrm{cm}^{2}$. As fibras de juta foram adquiridas junto ao comércio de Belém do Pará, na forma de tecidos tramados no estilo plano (tela), fabricados pela Companhia Têxtil de Castanhal e foram usadas na forma de tecido de gramatura média de $0,0225 \mathrm{~g} / \mathrm{cm}^{2}$ e fios alinhados. As fibras de palha da costa foram adquiridas no comércio da cidade de Belém, na forma de tecidos tramados no estilo plano, com gramatura de $0,0237 \mathrm{~g} / \mathrm{cm}^{2}$.

\subsection{Fabricação dos Compósitos}

Foram fabricadas placas de compósitos de acordo com a arquitetura mostrada na figura 1. Inicialmente as fibras de reforço, com massa já devidamente determinada em balança analítica com precisão de 0,0001 g, 
sempre em duas camadas quando utilizadas na forma de tecidos, foram dispostas sobre um molde plano previamente tratado com cera desmoldante. Em seguida foram posicionados sobre as fibras o tecido desmoldante (peel ply), utilizado para facilitar a remoção das camadas superiores, o filme perfurado e o meio distribuidor, que têm a função de promover o fluxo pela criação de canais para a passagem de resina, mangueiras espirais e por fim o saco de vácuo. Todo o sistema foi então vedado pelo uso da fita selante.

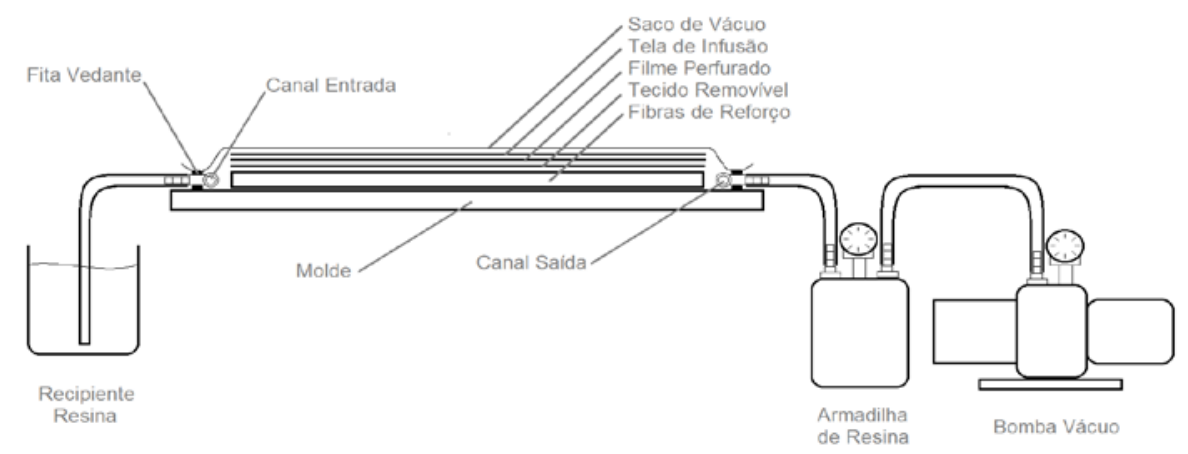

Figura 1: Desenho esquemático do processo de fabricação dos compósitos por infusão.

Os compósitos com reforço de curauá, juta ou palha da costa foram fabricados variando-se a disposição das fibras, na forma de tecido ou unidirecionalmente alinhadas. Foram utilizados dois níveis diferentes de vácuo de modo a se avaliar a influência desta variável sobre as propriedades do compósito e parâmetros do processo de fabricação, 53,3 kPa e 101,3 kPa.

Tabela 1: Parâmetros avaliados no processamento dos compósitos

\begin{tabular}{c|c|c}
\hline FIBRA DE REFORÇO & DISPOSIÇÃO/TRATAMENTO & NÍVEL DE VÁCUO (KPa) \\
\hline \multirow{4}{*}{ Curauá } & Fibras alinhadas & 53,3 \\
\cline { 2 - 3 } & Fibras alinhadas & 101,3 \\
\cline { 2 - 3 } & Tecido Plano & 101,3 \\
\hline \multirow{4}{*}{ Juta } & Fios alinhados & 53,3 \\
\cline { 2 - 3 } & Fios alinhados & 101,3 \\
\cline { 2 - 3 } & Tecido Plano & 53,3 \\
\cline { 2 - 3 } & Tecido Plano & 101,3 \\
\hline \multirow{4}{*}{ Palha da Costa } & Fibras alinhadas & 53,3 \\
\cline { 2 - 3 } & Fibras alinhadas & 101,3 \\
\cline { 2 - 3 } & Tecido plano & 53,3 \\
\cline { 2 - 3 } & Tecido plano & 101,3 \\
\hline
\end{tabular}

\subsection{Caracterização dos Compósitos Fabricados}

Os compósitos fabricados foram caracterizados quanto à sua massa específica $(\rho)$, porosidade $\left(\mathrm{V}_{\mathrm{V}}\right)$, resistência à tração $\left(\sigma_{t}\right)$, deformação na ruptura $\left(\varepsilon_{\text {rup }}\right)$, módulo de elasticidade $(E)$ e resistência ao impacto Charpy.

A determinação da massa específica dos compósitos foi realizada segundo os procedimentos descritos em LEVY NETO e PARDINI [4] que consiste na determinação do volume do compósito pela medida do empuxo produzido por uma amostra imersa em água destilada com o auxílio de uma balança analítica com precisão de $0,0001 \mathrm{~g}$.

As frações mássicas de fibra e matriz foram determinadas, no caso dos compósitos reforçados com tecidos, a partir da extração de amostras circulares de diâmetro $50 \mathrm{~mm}$, correlacionando-se a massa das amostras com a massa das fibras calculadas a partir da gramatura do tecido utilizado em cada placa, previamente determinada. Nas placas em que o reforço se deu na forma de fios alinhados, as frações mássicas foram calculadas a partir do conhecimento da massa de fibras adicionadas à placa e a massa final da placa produzida, considerando-se uma regular distribuição de matriz e fibra ao longo da mesma. 
A porosidade, ou fração volumétrica de vazios (Vv) foi determinada a partir da equação 1 [5].

$$
V_{V}=1-\rho_{c}\left(\frac{w_{f}}{\rho_{f}}+\frac{w_{m}}{\rho_{m}}\right)
$$

onde $V_{v}$ é a fração volumétrica de vazios; $\rho_{c}$ a massa específica do compósito; $w_{f}$ a fração mássica da fibra (\%); $w_{m}$ a fração mássica da matriz (\%); $\rho_{f}$ a massa específica da fibra $\left(\mathrm{g} / \mathrm{cm}^{3}\right)$ e $\rho_{m}$ a massa específica da matriz $\left(\mathrm{g} / \mathrm{cm}^{3}\right)$.

A fração volumétrica das fibras foi calculada a partir da equação 2 [6].

$$
V_{f}=\frac{\rho_{c}}{\rho_{f}} W_{f}
$$

A resistência à tração $\left(\sigma_{t}\right)$, o módulo de elasticidade $(E)$ e a deformação na ruptura $\left(\varepsilon_{\text {rup }}\right)$ dos compósitos foram determinados de acordo com os procedimentos estabelecidos na norma ASTM D 3039. Adicionalmente foi determinado o módulo de tenacidade $\left(\mathrm{U}_{\mathrm{t}}\right)$ em tração dos corpos de prova, pela integração da área sob a curva tensão-deformação, desde o início do ensaio até a ruptura do corpo de prova. Os ensaios foram realizados em uma máquina de ensaio universal AROTEC WDW 100E, com velocidade de ensaio de 2 $\mathrm{mm} / \mathrm{min}$, sendo ensaiados 6 corpos de prova de cada condição testada. Os ensaios de impacto Charpy foram realizados seguindo os procedimentos estabelecidos na norma ASTM D 5942 sendo ensaiados seis corpos de prova de cada variação testada.

\section{RESULTADOS E DISCUSSÃO}

\subsection{Resistência à Tração}

A tabela 2 e a figura 2 apresentam os resultados do ensaio de resistência à tração dos compósitos reforçados com fibras de curauá. A linha tracejada mostrada na figura 2 indica o limite de resistência à tração da matriz plena de poliéster (34,35 MPa).

\begin{tabular}{|c|c|c|c|c|c|c|c|}
\hline $\begin{array}{c}\text { REFORÇOI } \\
\text { DISPOSIÇÃO }\end{array}$ & $\begin{array}{l}\text { VÁCUO } \\
\text { (KPa) }\end{array}$ & $\begin{array}{l}V_{F} \\
(\%)\end{array}$ & $\begin{array}{l}V_{v} \\
(\%)\end{array}$ & $\begin{array}{c}\sigma_{\mathrm{T}}(\mathrm{MPa}) \\
M E ́ D I A \pm E P^{(*)}\end{array}$ & $\begin{array}{l}\varepsilon_{\text {RUP }}(\mathrm{mm} / \mathrm{mm}) \\
M E ́ D I A \pm E P^{(*)}\end{array}$ & $\begin{array}{c}\text { E (GPa) } \\
\text { MÉDIA } \pm \text { EP(*) }^{(*)}\end{array}$ & $\begin{array}{l}\mathrm{U}_{\mathrm{T}}\left(\mathrm{KN} \cdot \mathrm{m} / \mathrm{m}^{3}\right) \\
M E ́ D I A \pm E P^{(*)} \\
\text { MEIA }\end{array}$ \\
\hline $\begin{array}{c}\text { Fibras Curauá } \\
\text { Alinhadas }\end{array}$ & 53,3 & 37 & 2,51 & $70,92 \pm 2,39$ & $0,029 \pm 0,002$ & $2,613 \pm 0,196$ & $\begin{array}{c}1186,302 \\
\pm 136,222\end{array}$ \\
\hline $\begin{array}{c}\text { Fibras Curauá } \\
\text { Alinhadas }\end{array}$ & 101,3 & 38 & 7,43 & $86,71 \pm 2,09$ & $0,028 \pm 0,001$ & $3,883 \pm 0,233$ & $\begin{array}{l}1262,448 \\
\pm 126,877\end{array}$ \\
\hline $\begin{array}{l}\text { Tecido Plano } \\
\text { Curauá }\end{array}$ & 101,3 & 38 & 5,32 & $30,10 \pm 3,88$ & $0,025 \pm 0,002$ & $1,113 \pm 0,099$ & $\begin{array}{l}486,008 \\
\pm 87,620\end{array}$ \\
\hline
\end{tabular}

Tabela 2: Resultados do ensaio de resistência à tração dos compósitos reforçados com fibras de curauá.

(*) Erro Padrão

Os compósitos fabricados com fibras alinhadas de curauá demostraram que com a elevação do nível de vácuo de 53,3 kPa para 101,3 kPa, obteve-se um ganho no limite de resistência à tração de 22,2\%. Frequentemente fibras naturais reforçando compósitos de matriz polimérica apresentam fraca adesão fibra/matriz [7], necessitando de tratamento superficial que modifique a superfície da fibra, alterando principalmente sua rugosidade [8, 9]. A natureza inerentemente polar e hidrofílica das fibras lignocelulósicas e as características apolares da maioria dos polímeros resultam em uma interação ineficiente na interface [10], constituindo o ancoramento mecânico como o principal mecanismo de adesão fibra/matriz em compósitos reforçados com fibras naturais. Dado o grau de porosidade e maciez das fibras naturais, à medida que o nível de vácuo aumenta, apesar do maior gradiente de pressão dentro da câmara de vácuo durante o processo de infusão, a permeabilidade diminui [7], diminuindo assim a velocidade de avanço da frente de impregnação, o que permite uma maior saturação das fibras pelo polímero, que preenche melhor as reentrâncias da fibra, melhorando o ancoramento mecânico e contribuindo para a elevação de seu desempenho mecânico em tração. 


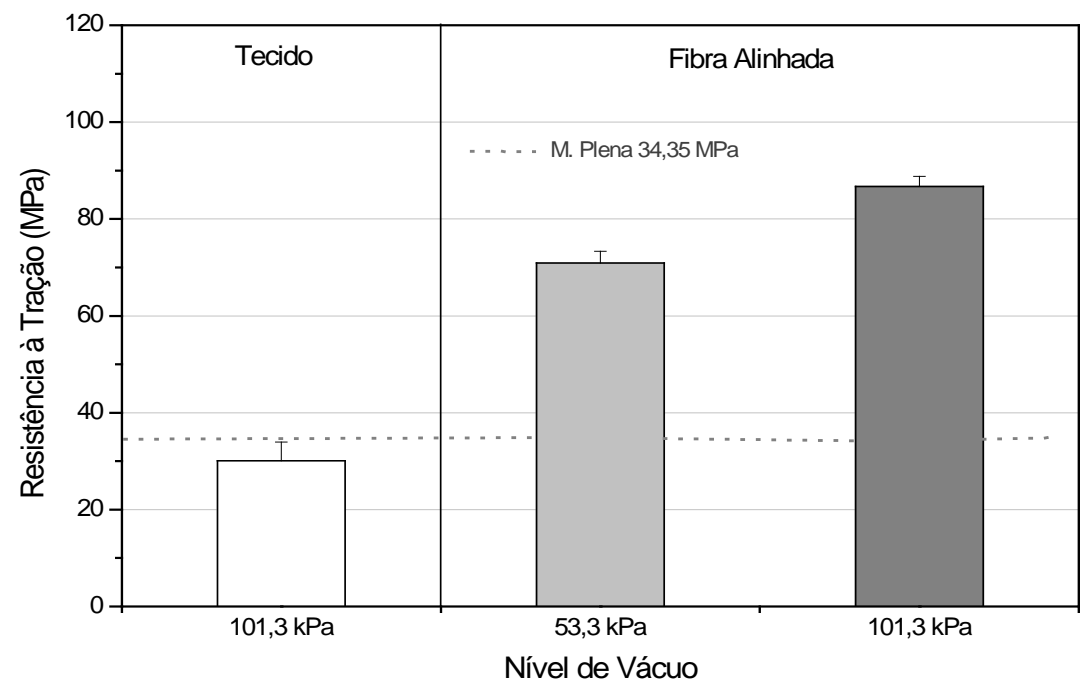

Figura 2: Resistência à Tração dos Compósitos reforçados com fibras de curauá.

Comparando-se para o mesmo nível de vácuo (101,3 kPa), os compósitos fabricados com tecido plano de curauá apresentaram um limite de resistência à tração 65\% inferior àqueles reforçados com fibras alinhadas. A despeito do fato de que na configuração em tecido somente $50 \%$ das fibras ficam alinhadas à direção do carregamento, o que diminui sua eficiência como reforço comparado às filhas contínuas alinhadas, a resistência da interface, quando seu principal mecanismo é a adesão mecânica, normalmente não é de grande magnitude quando submetida a esforços de tensão transversal [4, 11]. GOMES et al. [12], produzindo compósitos por compressão a quente de fibras alinhadas de curauá reforçando uma matriz biodegradável encontrou uma redução de 95\% dos compósitos solicitados na direção transversal ao alinhamento das fibras em relação aos ensaiados na direção do alinhamento longitudinal destas. A figura 3 mostra a superfície de fratura de um corpo de prova reforçado com tecido de curauá. Pode-se observar que as fibras alinhadas ao carregamento sofreram ruptura, mas aquelas perpendiculares à carga somente deixaram uma impressão na matriz, praticamente sem rompimento da fibra.

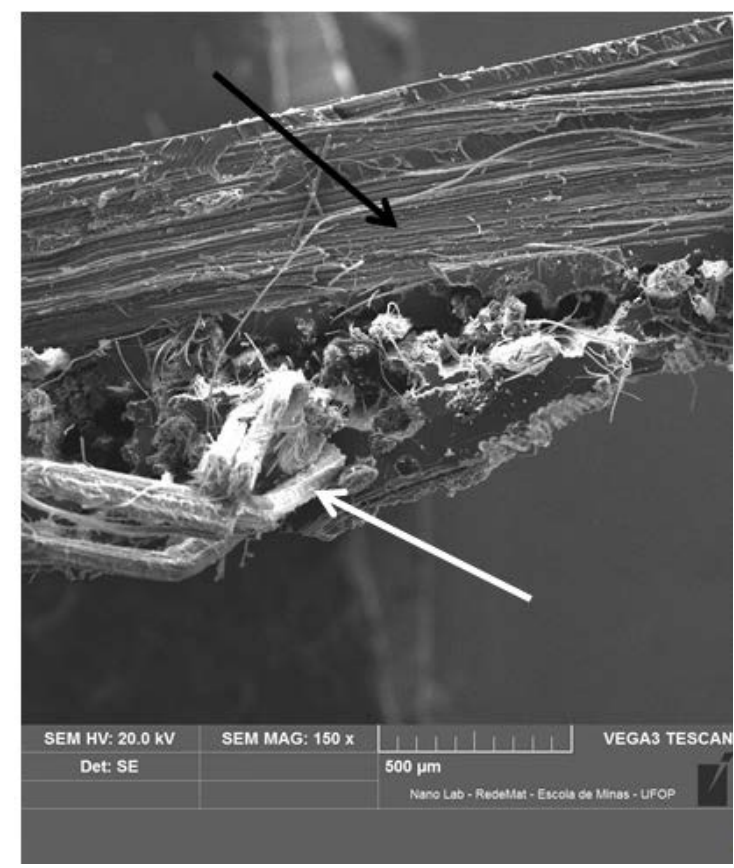

Figura 3: Superfície de fratura de corpo de prova reforçado com tecido plano de curauá. A seta branca indica fibras perpendiculares à superfície de fratura descoladas da matriz e rompidas e a seta preta mostra a impressão de uma fibra longitudinal à superfície de fratura que descolou. 
A figura 4 ilustra o comportamento tensão x deformação de corpos de prova típicos de cada uma das séries reforçadas com fibras de curauá. O efeito do intertravamento mecânico entre o reforço e a matriz potencializado pelo maior nível de vácuo se reflete na rigidez dos compósitos. Os compósitos fabricados com fibras contínuas alinhadas sob vácuo de $101,3 \mathrm{kPa}$ apresentaram módulo de elasticidade 48,6\% superiores àqueles fabricados sob vácuo de 53,3 kPa. À medida que a eficiência da interface é incrementada, a rigidez do compósito tende a ser dominada pela rigidez da fibra, muito mais dura e rígida que a matriz de poliéster. A fraca interação das fibras transversais à direção de solicitação contribui para a redução do desempenho dos compósitos reforçados com tecido comparados aos reforçados com fibras alinhadas.

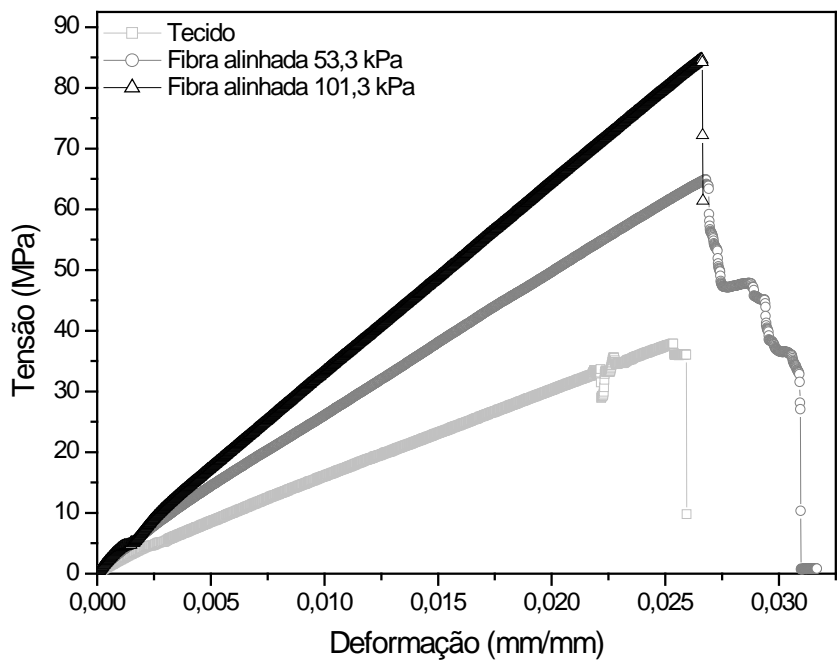

Figura 4: Comportamento Tensão x Deformação de corpos de prova típicos de compósitos reforçados com fibras de curauá.

A tabela 3 e a figura 5 mostram os resultados de resistência à tração dos compósitos reforçados com fibras de juta. Os dados mostram que em relação à resistência à tração da matriz (34,36 MPa), somente os compósitos fabricados com fios alinhados de juta tiveram desempenho superior, ficando os demais aquém deste limite.

Tabela 3: Resultados do ensaio de resistência à tração dos compósitos reforçados com fibras de juta.

\begin{tabular}{|c|c|c|c|c|c|c|c|}
\hline $\begin{array}{c}\text { REFORÇOI } \\
\text { DISPOSIÇÃOO }\end{array}$ & $\begin{array}{c}\text { VÁCUO } \\
(\mathrm{KPa})\end{array}$ & $\begin{array}{l}V_{F} \\
(\%)\end{array}$ & $\begin{array}{l}V_{v} \\
(\%)\end{array}$ & $\begin{array}{c}\sigma_{\mathrm{T}}(\mathrm{MPa}) \\
M E ́ D I A \pm E P^{(*)}\end{array}$ & $\begin{array}{l}\varepsilon_{\text {RUP }}(\mathrm{mm} / \mathrm{mm}) \\
M E ́ D I A \pm \mathrm{EP}^{(*)} \\
\end{array}$ & $\begin{array}{c}E(G P a) \\
M E ́ D I A \pm E P^{(*)}\end{array}$ & $\begin{array}{l}\mathrm{U}_{\mathrm{T}}\left(\mathrm{KN} \cdot \mathrm{m} / \mathrm{m}^{3}\right) \\
M E ́ D I A \pm E P^{(*)} \\
\end{array}$ \\
\hline Fios Juta alinhados & 53,3 & 32,0 & 7,94 & $53,18 \pm 2,24$ & $0,024 \pm 0,001$ & $2,388 \pm 0,145$ & $\begin{array}{r}627,690 \\
\pm 38,202 \\
\end{array}$ \\
\hline Fios Juta alinhados & 101,3 & 31,0 & 19,0 & $44,55 \pm 4,95$ & $0,027 \pm 0,001$ & $1,808 \pm 0,111$ & $\begin{array}{r}639,079 \\
\pm 57,612 \\
\end{array}$ \\
\hline Tecido Plano Juta & 53,3 & 19,0 & 12,3 & $22,66 \pm 2,04$ & $0,028 \pm 0,001$ & $0,825 \pm 0,023$ & $\begin{array}{l}378,930 \\
\pm 16,557 \\
\end{array}$ \\
\hline Tecido Plano Juta & 101,3 & 20,0 & 4,2 & $23,66 \pm 3,32$ & $0,038 \pm 0,003$ & $1,167 \pm 0,077$ & $\begin{array}{l}538,560 \\
\pm 94,564\end{array}$ \\
\hline
\end{tabular}

(*) Erro Padrão

Diferentemente do que foi observado para os compósitos reforçados com fibras de curauá, os compósitos reforçados com fios de juta alinhados apresentaram um decréscimo de $16 \%$ no limite de resistência à tração à medida que o nível de vácuo passou de 53,3 kPa para 101,3 kPa. Parte desta diferença se deve ao alto nível de porosidade apresentado pelo compósito fabricado sob vácuo mais elevado (19\%) em relação ao fabricado sob vácuo de 53,3 kPa (7,94\%). 


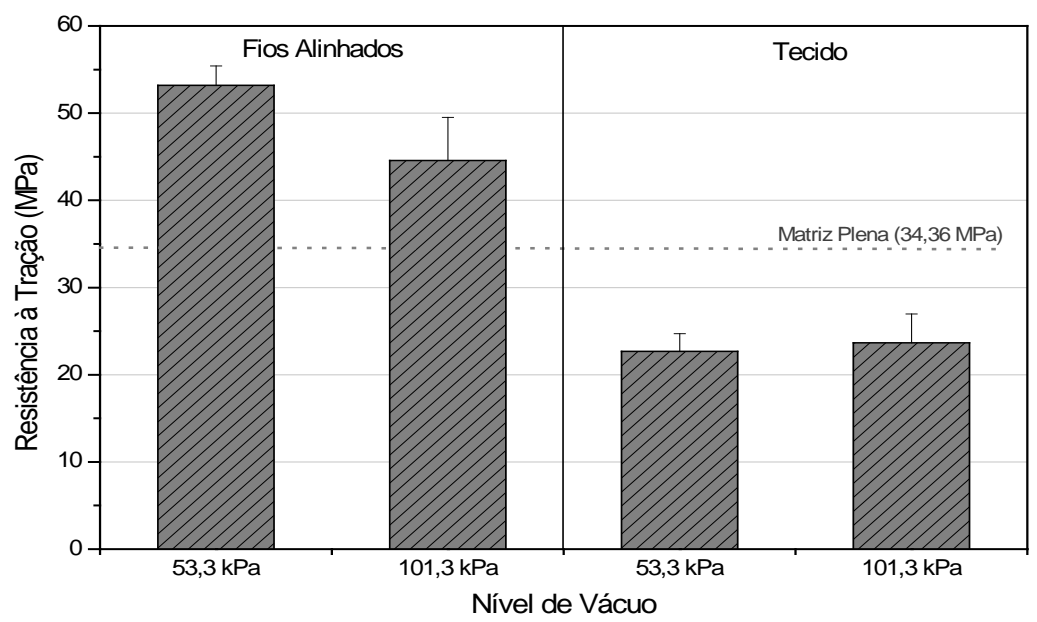

Figura 5: Resistencia à Tração dos compósitos reforçados com fibras de juta

A Compactação do tecido e sua permeabilidade são estreitamente relacionadas em função da compactação dos tecidos alterar a geometria e tamanho dos canais através dos quais o líquido de impregnação flui, tendo, por conseguinte, um impacto direto sobre as propriedades mecânicas do compósito [13]. Os tecidos de fibra de juta são constituídos de fios com diâmetro médio de 0,62 mm. Esse diâmetro considerável dificulta o preenchimento dos vazios interfios durante a compressão do tecido, se refletindo no nível de compactação que o compósito pode alcançar. Isto contribui para a redução da fração de fibra nos compósitos com reforço na forma de tecido quando comparados àqueles com reforço na forma de fios alinhados, como demonstrado na tabela 3. A figura 6 mostra a superfície de fratura de um compósito reforçado com tecido de juta, aonde se pode verificar o quanto o diâmetro dos fios é representativo em relação à espessura da placa.

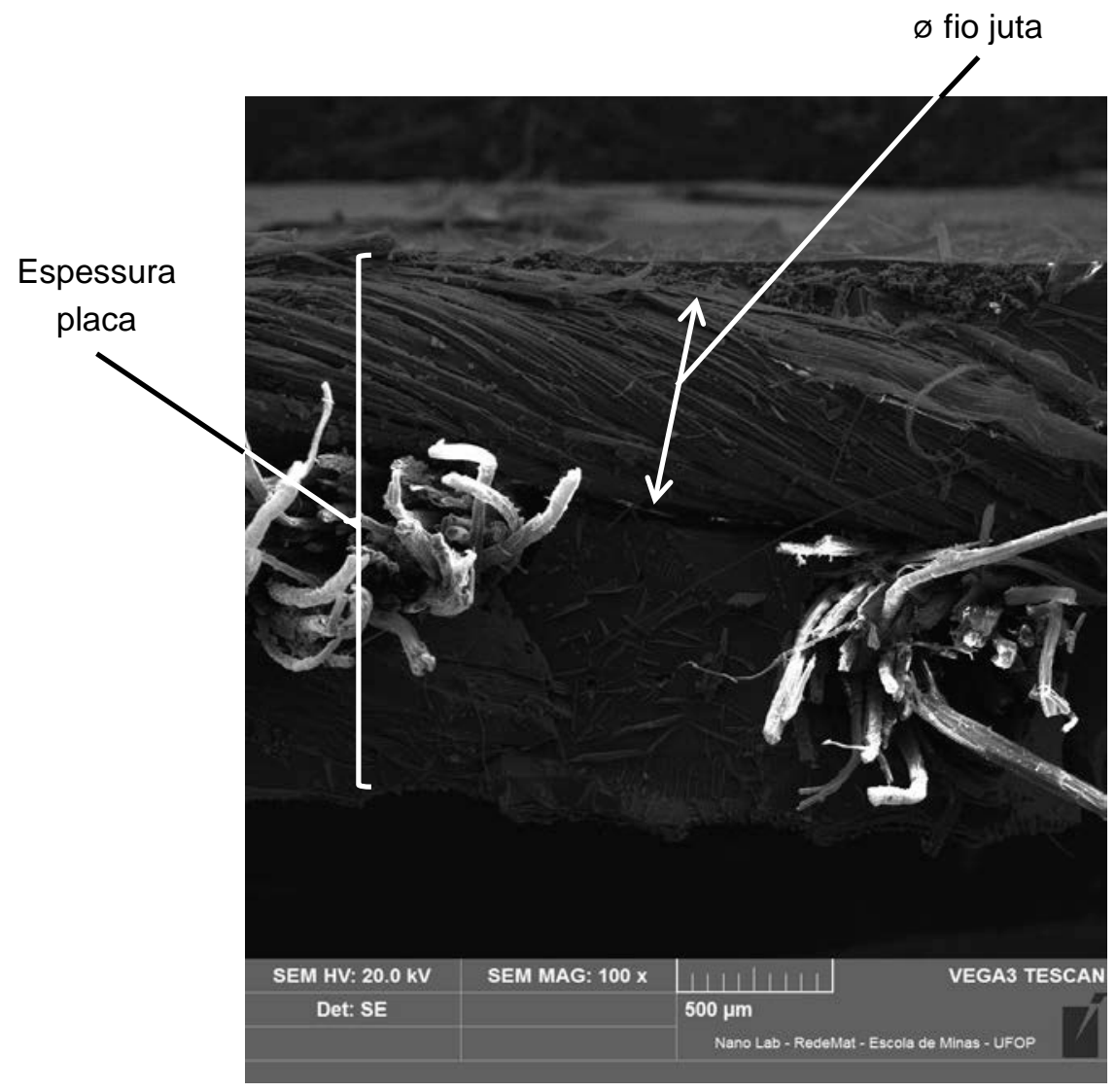

Figura 6: Superfície de fratura de compósito reforçado com tecido plano de juta. 
Além do diâmetro elevado, os fios de juta possuem um ângulo superficial de torção de $15^{\circ}$. À medida que se torce e aperta a estrutura do fio, a permeabilidade interna deste é reduzida [13], dificultando a impregnação das fibras internas. Paralelamente, a torção dos fios eleva o nível de tensão das fibras mais externas, o que, aliado à deformação dos fios para níveis de pressão de compactação mais elevados [7], prejudica a infiltração da matriz no fio, diminuindo a eficiência da interface, afetando tanto o limite de resistência à tração, como o módulo de elasticidade, que foi reduzido de 24,3\% quando da elevação do nível de vácuo de 53,3 para 101,3 kPa durante o processo de infusão.

A figura 7 mostra a seção transversal de corpos de prova reforçados com fios de juta. Nas imagens pode-se observar que o interior de alguns fios apresentam ausência de matriz, caracterizando a porosidade intrafio.

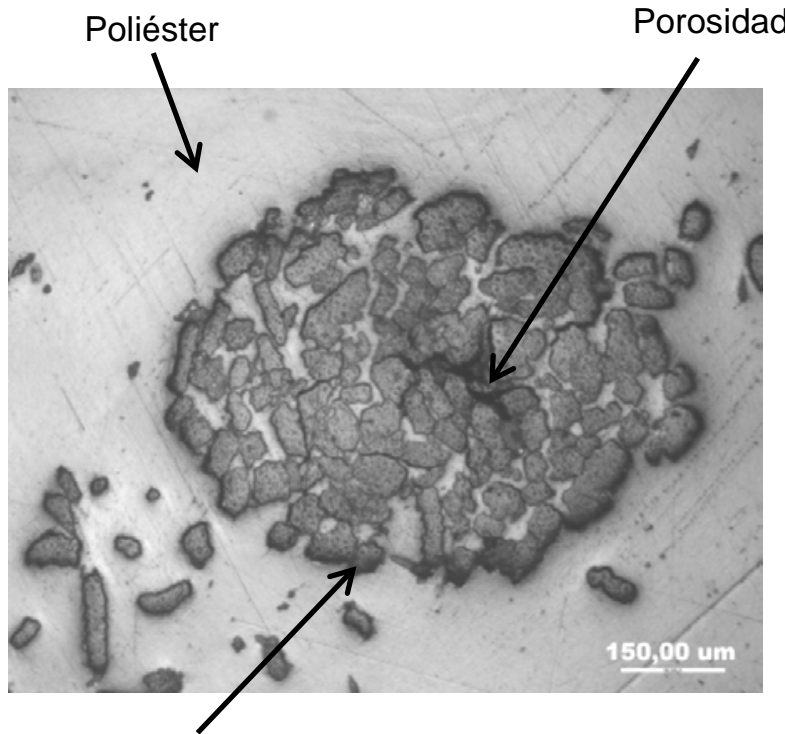

Fibras Juta

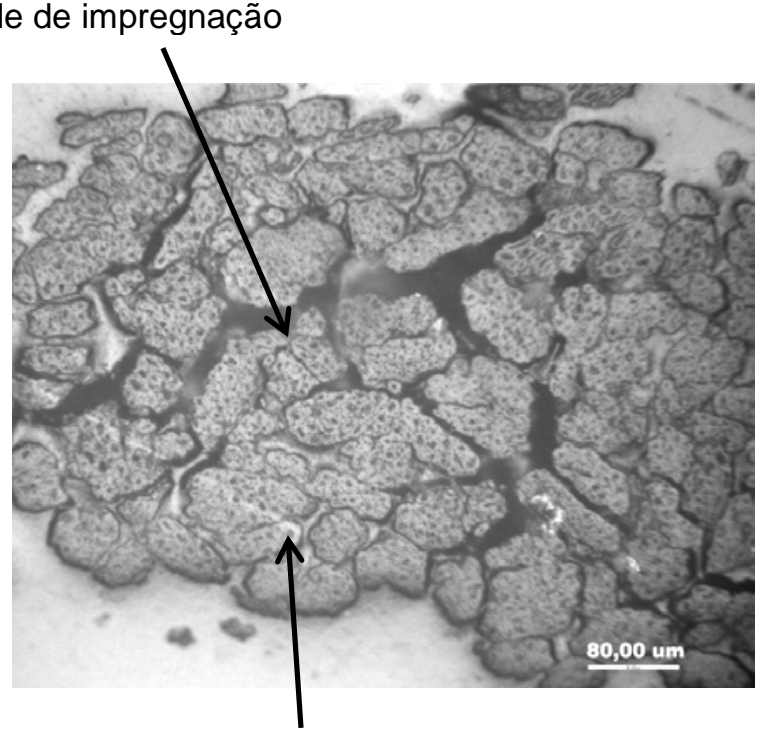

Fibras Juta

Figura 7: Seção transversal de compósitos reforçados com fibras de juta. Pode-se verificar que o interior de fios mais espessos apresentam ausência da matriz de poliéster.

A figura 8 ilustra o comportamento tensão x deformação de corpos de prova típicos dos compósitos reforçados com fios de juta. No gráfico pode-se verificar que os compósitos fabricados com fios alinhados de juta, além de alcançarem um limite de resistência à tração mais elevado, mostram um nível de rigidez maior em relação aos compósitos reforçados com tecido plano de juta.

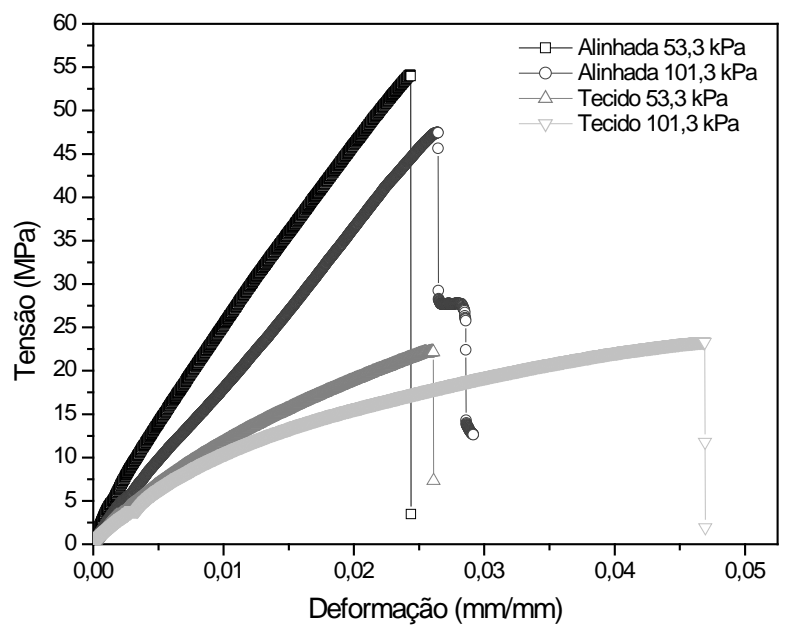

Figura 8: Resistencia à Tração dos Compósitos reforçados com fibras de juta. 
A tabela 4 mostra os resultados obtidos no ensaio de resistência à tração dos compósitos reforçados com fibras de palha da costa. Os dados mostram que o desempenho em tração de todos os compósitos reforçados com palha da costa, diferentemente do que foi observado nas placas fabricadas com reforço de curauá e juta, ficaram aquém da resistência obtida para a matriz plena (34,36 MPa). Isso se deve em parte à resistência da fibra de palha da costa, 58,48\% inferior à da fibra de curauá e 24,07\% inferior à fibra de juta. Outro aspecto a ser considerado nesta análise é a interface fibra/matriz. A figura 9 mostra superfícies de fratura de corpos de prova reforçados com fibras de palha da costa. Analisadas ao microscópio eletrônico de varredura, a superfície das fibras expostas na fratura mostram quase que total ausência de vestígios de matriz, o que evidencia uma baixa adesão interfacial.

Tabela 4: Resultados do ensaio de resistência à tração de compósitos reforçados com fibras de palha da costa.

\begin{tabular}{|c|c|c|c|c|c|c|c|}
\hline $\begin{array}{c}\text { REFORÇOI } \\
\text { DISPOSIÇÃOO }\end{array}$ & $\begin{array}{l}\text { VÁCUO } \\
\text { (KPa) }\end{array}$ & $\begin{array}{l}V_{F} \\
(\%)\end{array}$ & $\begin{array}{l}V_{v} \\
(\%)\end{array}$ & $\begin{array}{c}\sigma_{\mathrm{T}}(\mathrm{MPa}) \\
M E \text { MIA }^{(*) \mathrm{EP}^{(*)}}\end{array}$ & $\begin{array}{l}\varepsilon_{\text {RUP }}(\mathrm{mm} / \mathrm{mm}) \\
M E ́ D I A \pm E P^{(*)}\end{array}$ & $\begin{array}{c}E(G P a) \\
\left.M E ́ D I A \pm E P^{*}\right)\end{array}$ & $\begin{array}{l}\mathrm{U}_{\mathrm{T}}\left(\mathrm{KN} \cdot \mathrm{m} / \mathrm{m}^{3}\right) \\
M E ́ D I A \pm E P^{(*)}\end{array}$ \\
\hline $\begin{array}{c}\text { Fibras alinhadas } \\
\text { Palha da Costa }\end{array}$ & 53,3 & 45,0 & 2,21 & $23,59 \pm 5,52$ & $0,017 \pm 0,006$ & $2,325 \pm 0,180$ & $\begin{array}{r}425,965 \\
\pm 96,370 \\
\end{array}$ \\
\hline $\begin{array}{l}\text { Fibras alinhadas } \\
\text { Palha da Costa }\end{array}$ & 101,3 & 40,0 & 9,57 & $22,97 \pm 1,58$ & $0,022 \pm 0,001$ & $1,303 \pm 0,090$ & $\begin{array}{r}323,046 \\
\pm 46,853 \\
\end{array}$ \\
\hline $\begin{array}{c}\text { Tecido plano Palha } \\
\text { da Costa }\end{array}$ & 53,3 & 35,0 & 9,92 & $14,42 \pm 0,90$ & $0,023 \pm 0,001$ & $1,010 \pm 0,059$ & $\begin{array}{l}203,675 \\
\pm 10,886\end{array}$ \\
\hline $\begin{array}{c}\text { Tecido plano Palha } \\
\text { da Costa }\end{array}$ & 101,3 & 43,0 & 9,07 & $20,27 \pm 1,88$ & $0,029 \pm 0,004$ & $0,913 \pm 0,124$ & $\begin{array}{l}290,275 \\
\pm 52,410\end{array}$ \\
\hline
\end{tabular}

(*) Erro Padrão

O limite de resistência à tração e o módulo de elasticidade encontrados para os compósitos com fibras de palha da costa alinhadas fabricados sob vácuo de 101,3 kPa (22,97 MPa e 1,303 GPa, respectivamente), foram inferiores aos valores reportados por PORTELA et al. [15] (100,15 MPa e 1,66 GPa), trabalhando com $40 \%$ de fibras de buriti reforçando uma matriz de poliéster.
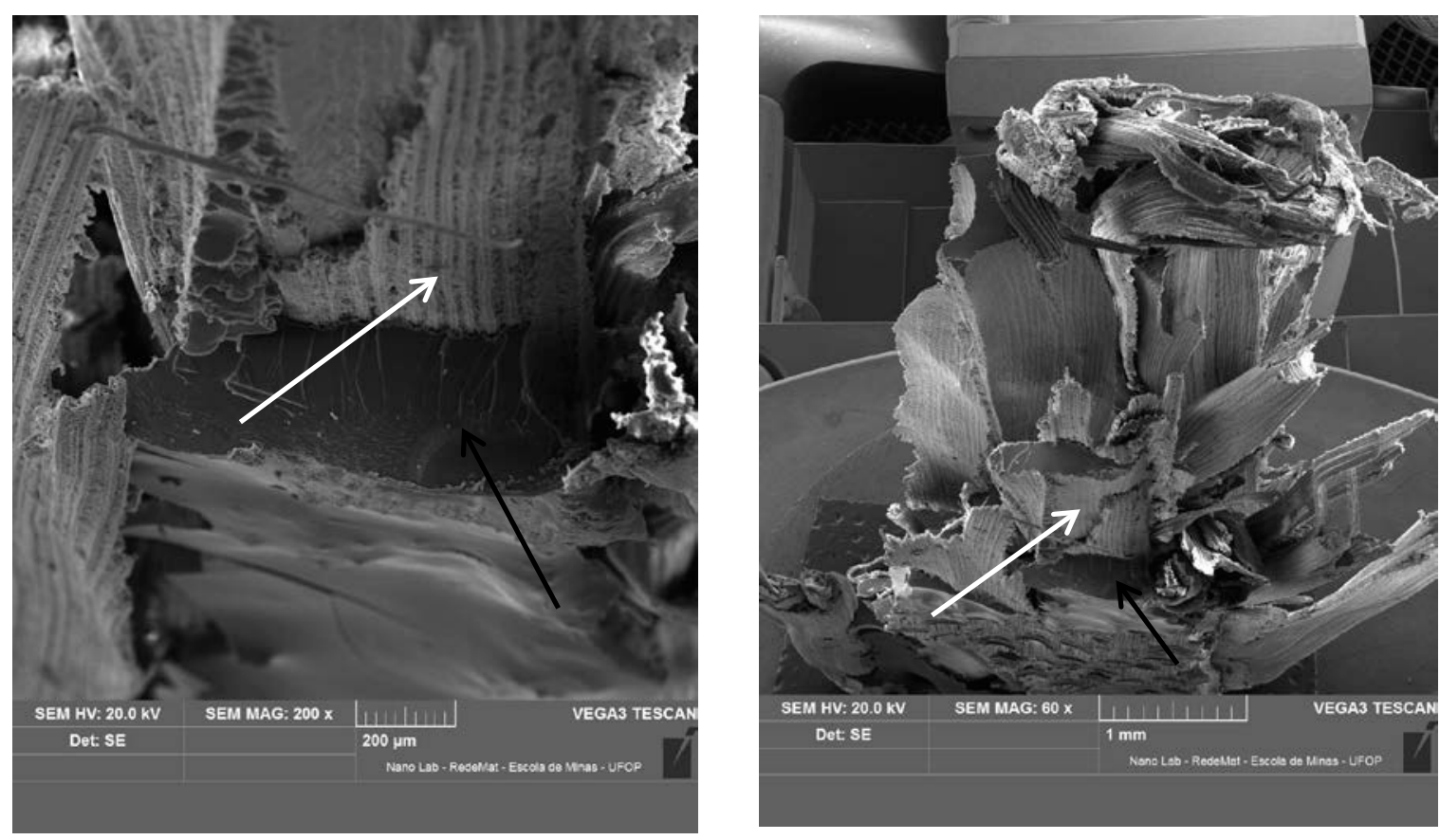

Figura 9: Superfícies de fratura de corpos de prova reforçados com fibras alinhadas de palha da costa. As setas pretas indicam a matriz de poliéster e as brancas as fibras de palha da costa praticamente isentas de matriz.

A análise dos resultados demonstrados na figura 10 mostra que não houve diferença significativa na resistência à tração dos compósitos em função da elevação do nível de vácuo utilizado na confecção das placas. Os compósitos fabricados com fibras alinhadas obtiveram praticamente o mesmo desempenho em tração 
para os dois níveis de vácuo testados, 53,3 kPa e 101,3 kPa. Os compósitos reforçados com tecido apresentaram um ganho de 40,57\% na resistência à tração com a elevação do nível de vácuo.

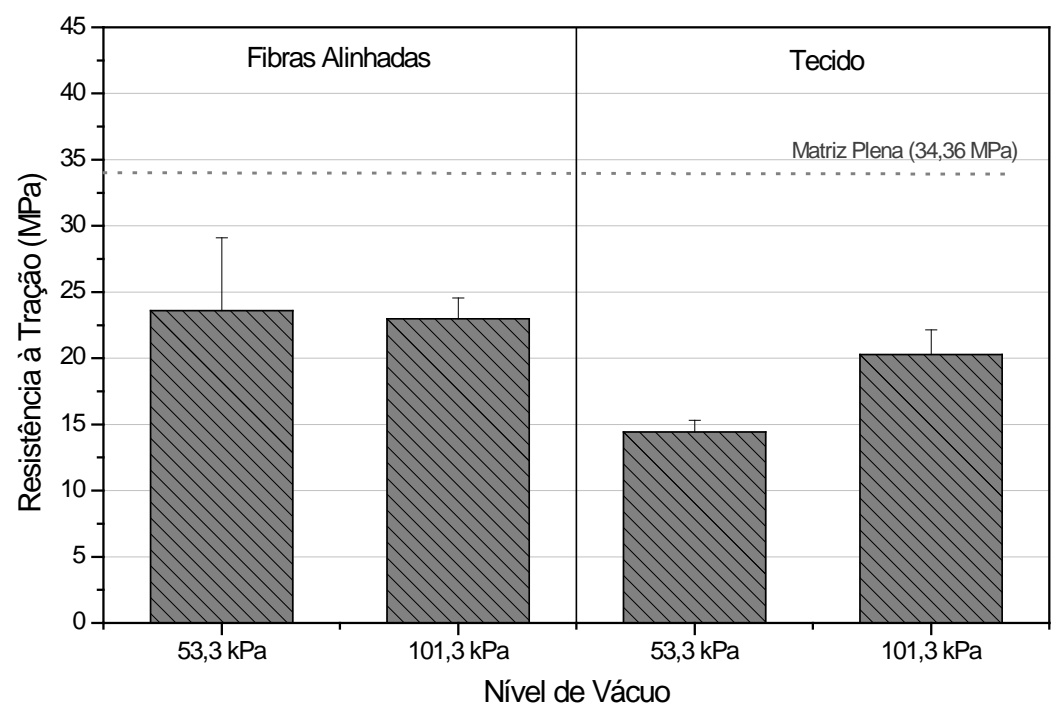

Figura 10: Resistencia à Tração dos Compósitos reforçados com fibras de palha da costa.

A figura 11 apresenta corpos de prova típicos de cada uma das placas reforçadas com palha da costa fabricadas. Como verificado para as demais fibras, os compósitos reforçados com fibras alinhadas apresentam maior limite de resistência à tração e maior rigidez quando comparados aos compósitos fabricados com tecido plano. Como anteriormente verificado, as placas com fibras alinhadas mostraram comportamento em tração muito semelhante, em limite de resistência e rigidez.

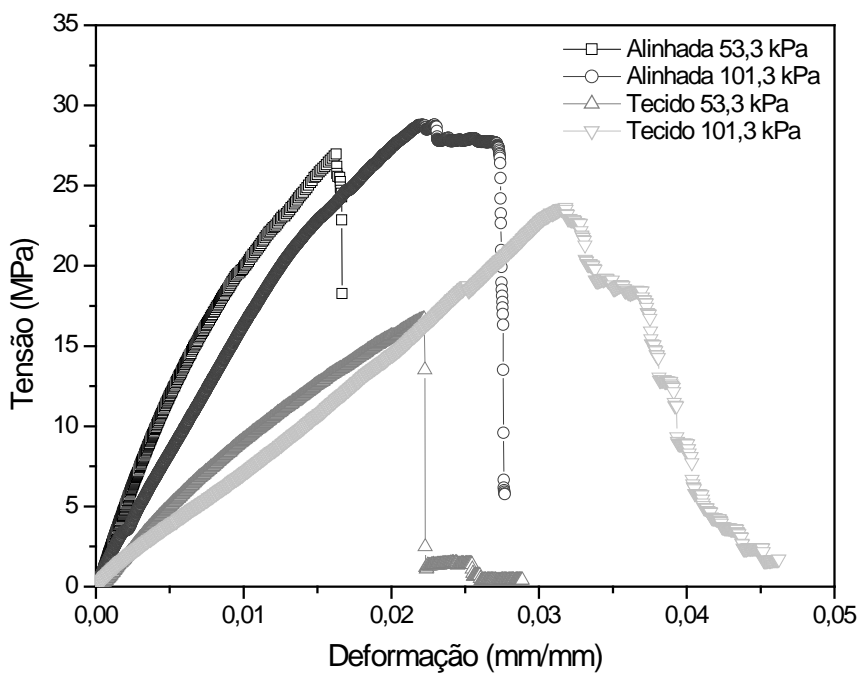

Figura 11: Resistencia à Tração dos Compósitos reforçados com fibras de palha da costa.

\subsection{Resistência ao Impacto Charpy}

A tabela 5 e a figura 12 apresentam os resultados obtidos no ensaio de resistência ao impacto Charpy para os compósitos reforçados com fibras alinhadas de curauá e tecido plano de curauá. Os dois mecanismos básicos de absorção de energia dos materiais são a criação de novas superfícies de fratura e a deformação do material.

No ensaio de impacto, o primeiro mecanismo a operar é a deformação do material e, sendo a energia incidente suficientemente alta, ocorre a iniciação e propagação da trinca, atuando como segundo mecanismo de absorção de energia. No caso dos compósitos, os mecanismos de absorção de energia de maior contribuição para a sua tenacidade ocorrem durante a propagação da trinca e são a extração das fibras e o descolamen- 
to da interface. Estes mecanismos consomem energia pela criação de uma maior área superficial de fratura dentro do compósito e pelo trabalho de fricção na interface [16]. As propriedades superiores da fibra de curauá favorecem os mecanismos de absorção de energia, principalmente pelo descolamento da interface e extração da fibra, haja vista a alta resistência desta.

Tabela 5: Resultados do ensaio de resistência ao impacto Charpy de compósitos reforçados com fibras de curauá.

\begin{tabular}{|c|c|c|c|c|}
\hline REFORÇO/DISPOSIÇÃO & $\begin{array}{l}\text { VÁCUO } \\
\text { (KPa) }\end{array}$ & $\begin{array}{l}V_{F} \\
(\%)\end{array}$ & $\begin{array}{l}V_{v} \\
(\%)\end{array}$ & $\begin{array}{l}\text { RESIST. IMP. CHARPY }\left(\mathrm{KJ} / \mathrm{m}^{2}\right) \\
\text { MÉDIA } \pm \text { EP }^{(*)}\end{array}$ \\
\hline Tecido Plano de Curauá & 101,3 & 39 & 5,32 & $6,14 \pm 0,57$ \\
\hline Fibras de Curauá alinhadas in natura & 53,3 & 37 & 2,51 & $24,93 \pm 2,85$ \\
\hline Fibras de Curauá alinhadas in natura & 101,3 & 38 & 7,43 & $14,49 \pm 1,75$ \\
\hline
\end{tabular}

(*) Erro Padrão

Os resultados apresentados na figura 12 mostram que os compósitos reforçados com fibras de curauá alinhadas apresentaram desempenho em impacto severamente superior aos compósitos reforçados com tecido. As placas reforçadas com fibras alinhadas fabricadas a 53,3 kPa alcançaram 24,93 kJ/m² de energia absorvida no impacto, desempenho 72\% superior àqueles fabricados sob vácuo de 101,3 kPa. O ganho em eficiência da interface alcançado para os compósitos com reforço de curauá fabricados sob níveis de vácuo mais elevados desfavorece os mecanismos de consumo de energia durante o ensaio de impacto, uma vez que a maior adesão mecânica fibra/matriz reduz a criação de novas superfícies pelo escorregamento da fibra.

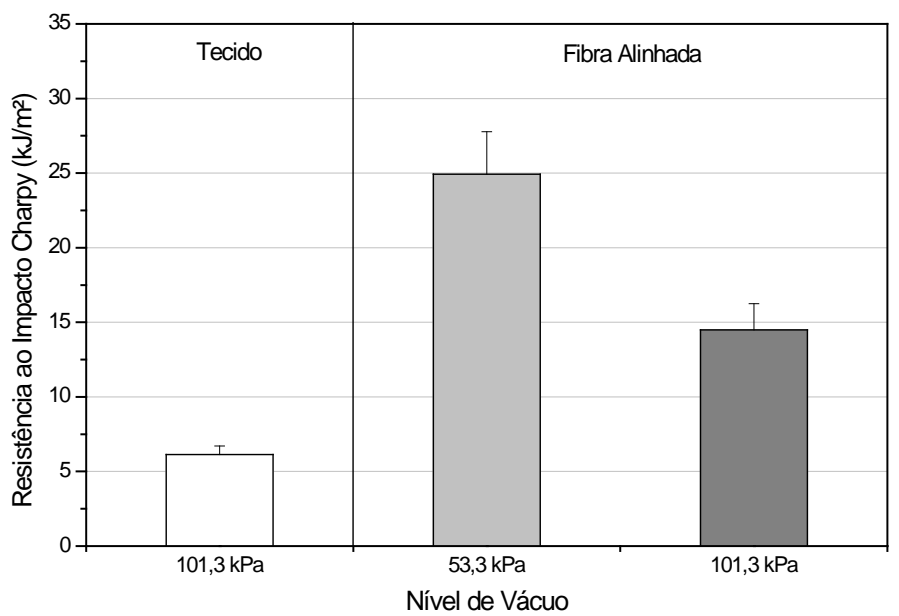

Figura 12: Resistencia ao Impacto Charpy dos compósitos reforçados com fibras de curauá.

Os resultados obtidos no ensaio de impacto Charpy dos compósitos reforçados com fios de juta alinhados e tecido plano de juta são apresentados na tabela 6 e figura 13. Como observado para os compósitos reforçados com fibras de curauá, os compósitos reforçados com fios alinhados apresentaram desempenho sob impacto consideravelmente mais elevado do que os de reforço na forma de tecido. Este desempenho está diretamente correlacionado à disposição da fibra, mas também à maior fração volumétrica de fibras alcançada nos compósitos com fios alinhados, pois como observado por SILVA [16] com o aumento da fração de fibra os principais mecanismos de absorção de energia são favorecidos, resultando em maior energia para a fratura. Análogo ao verificado no comportamento sob tração dos compósitos com reforço de fios de juta, a elevação do nível de vácuo no processo de fabricação comprometeu a eficiência da interface, majorando a energia consumida durante a fratura destes compósitos.

Tabela 6: Resultados do ensaio de resistência ao impacto Charpy de compósitos reforçados com fibras de juta. 


\begin{tabular}{|c|c|c|c|c|}
\hline REFORÇO/DISPOSIÇÃO & $\begin{array}{l}\text { VÁCUO } \\
\text { (KPa) }\end{array}$ & $\begin{array}{l}V_{F} \\
(\%)\end{array}$ & $\begin{array}{l}V_{v} \\
(\%)\end{array}$ & $\begin{array}{l}\text { RESIST. IMP. CHARPY }\left(\mathrm{KJ} / \mathrm{m}^{2}\right) \\
\text { MÉDIA } \pm \mathrm{EP}^{(*)}\end{array}$ \\
\hline Fios de Juta alinhados & 53,3 & 32,0 & 7,94 & $6,65 \pm 0,38$ \\
\hline Fios de Juta alinhados & 101,3 & 31,0 & 19,0 & $9,13 \pm 1,45$ \\
\hline Tecido Plano de Juta & 53,3 & 19,0 & 12,3 & $2,13 \pm 0,39$ \\
\hline Tecido Plano de Juta & 101,3 & 26,0 & 8,6 & $4,41 \pm 0,8$ \\
\hline
\end{tabular}

(*) Erro Padrão

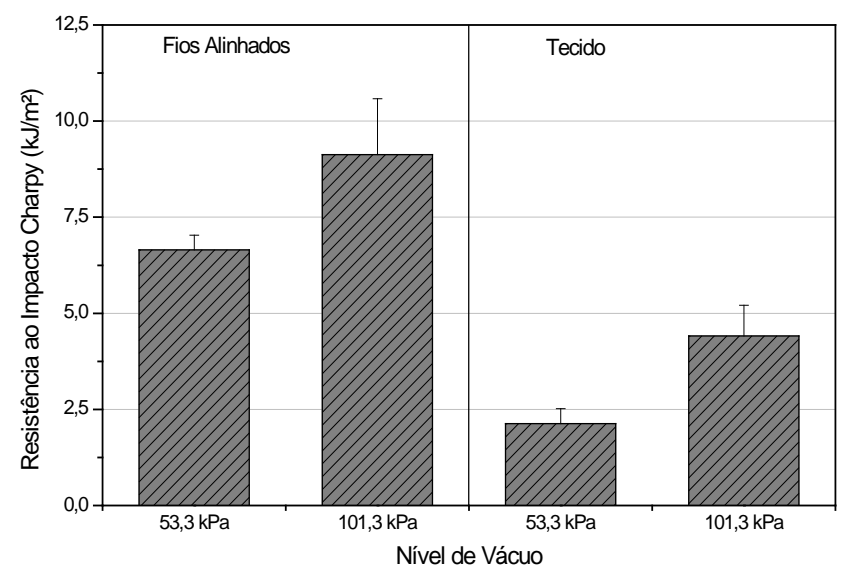

Figura 13: Resistencia ao Impacto Charpy dos compósitos reforçados com fibras de juta.

A figura 14 mostra a variação da resistência ao impacto Charpy dos compósitos reforçados com tecido de juta e sua relação com o módulo de tenacidade obtido no ensaio de tração. A tenacidade é um parâmetro que compreende tanto a resistência mecânica quanto a ductilidade do material, sendo, portanto adequado para a comparação com a energia absorvida no ensaio dinâmico por impacto. Os resultados mostram uma correlação direta entre a energia absorvida até a fratura no ensaio de tração e a energia absorvida por impacto Charpy. Tanto o módulo de tenacidade quanto a resistência ao impacto Charpy subiram com a elevação do vácuo de 53,3 para 101,3 kPa.

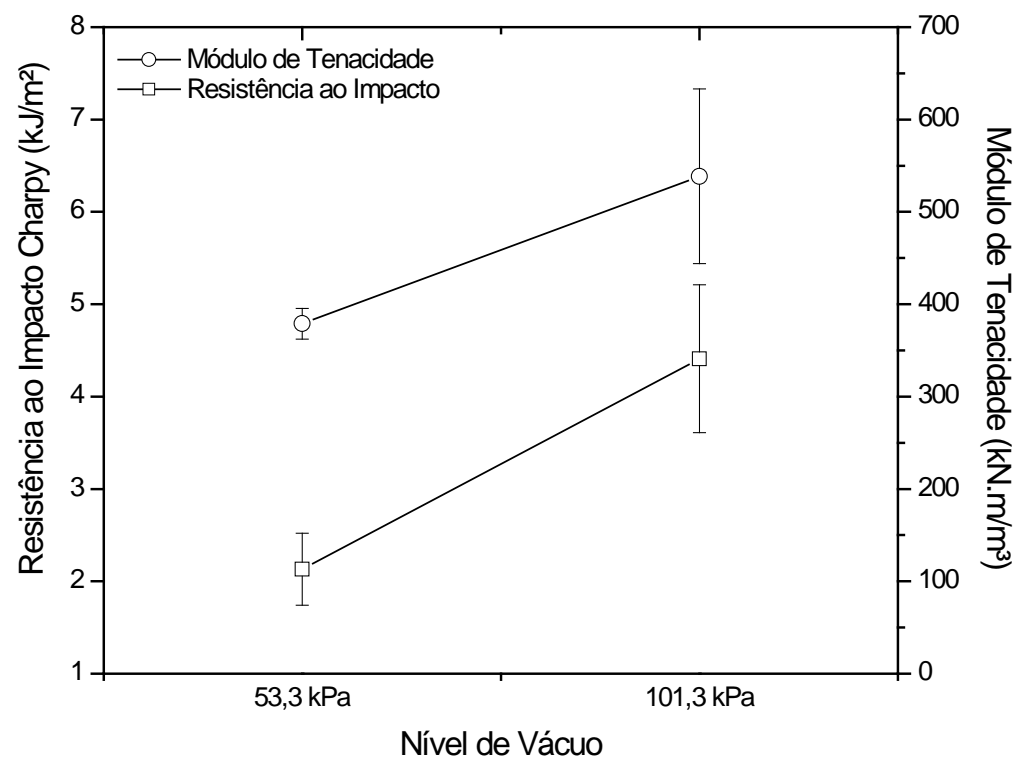

Figura 14: Resistência ao impacto Charpy e módulo de tenacidade de compósitos reforçados com tecido de juta. 
A tabela 7 e a figura 15 apresentam a resistência ao impacto Charpy obtida para os compósitos reforçados com fibras de palha da costa. Diferentemente do observado nos ensaios de resistência à tração, a elevação do nível de vácuo reduziu o desempenho dos compósitos reforçados tanto por fibras alinhadas quanto por tecido. Neste caso, os mecanismos de absorção de energia, que esperava-se serem favorecidos pela fraca adesão interfacial fibra matriz, não prevaleceram. Isso provavelmente se deu em função do modo como as fibras foram extraídas e utilizadas na confecção dos compósitos, na forma de pequenas fitas espiraladas, que agregam diversos monofilamentos da fibra, como pode ser observado na figura 16. A menor área superficial das fibras limita a absorção de energia durante a fratura.

Tabela 7: Resultados do ensaio de resistência ao impacto Charpy de compósitos reforçados com fibras de palha da costa.

\begin{tabular}{|c|c|c|c|c|}
\hline REFORÇO / DISPOSIÇÃO & $\begin{array}{l}\text { VÁCUO } \\
\text { (KPa) }\end{array}$ & $\begin{array}{l}V_{F} \\
(\%)\end{array}$ & $\begin{array}{l}V_{v} \\
(\%)\end{array}$ & $\begin{array}{l}\text { RESIST. IMP. CHARPY }\left(\mathrm{KJ} / \mathrm{m}^{2}\right) \\
\text { MÉDIA } \pm \mathrm{EP}^{(*)}\end{array}$ \\
\hline Fibras alinhadas de Palha da Costa & 53,3 & 45,0 & 2,21 & $6,53 \pm 1,08$ \\
\hline Fibras alinhadas de Palha da Costa & 101,3 & 40,0 & 9,57 & $4,70 \pm 0,93$ \\
\hline Tecido plano de Palha da Costa & 53,3 & 35,0 & 9,92 & $8,39 \pm 1,63$ \\
\hline Tecido plano de Palha da Costa & 101,3 & 43,0 & 9,07 & $2,36 \pm 0,48$ \\
\hline
\end{tabular}

$(*)$ Erro Padrão

A análise dos dados apresentados na figura 15 indica que para os compósitos com fibras alinhadas, houve um decréscimo de $28 \%$ na resistência ao impacto Charpy e para os corpos de prova reforçados por tecidos de $72 \%$.

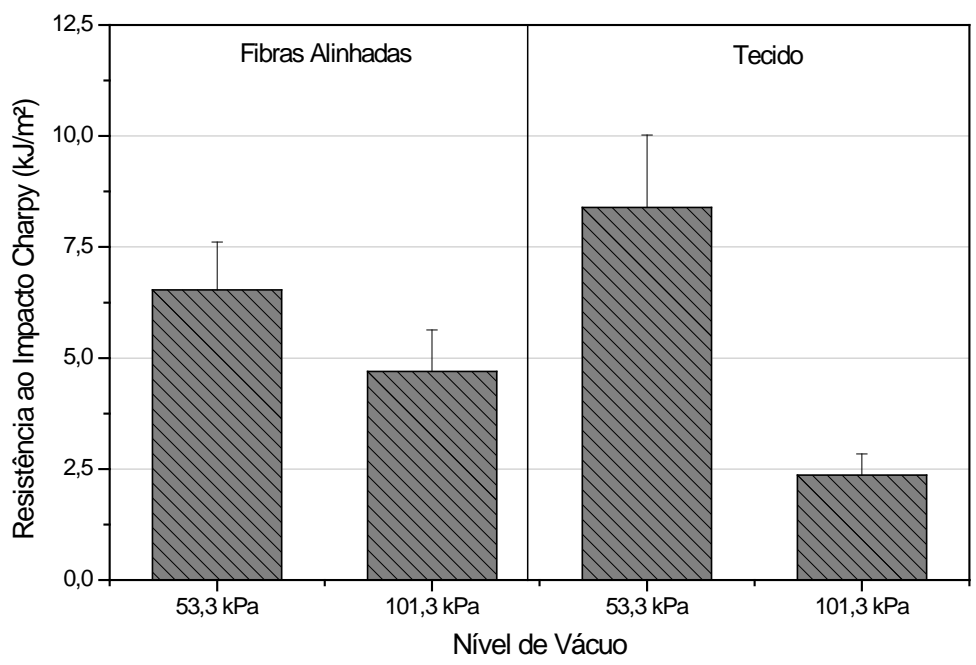

Figura 15: Resistencia ao Impacto Charpy dos compósitos reforçados com fibras de palha da costa. 


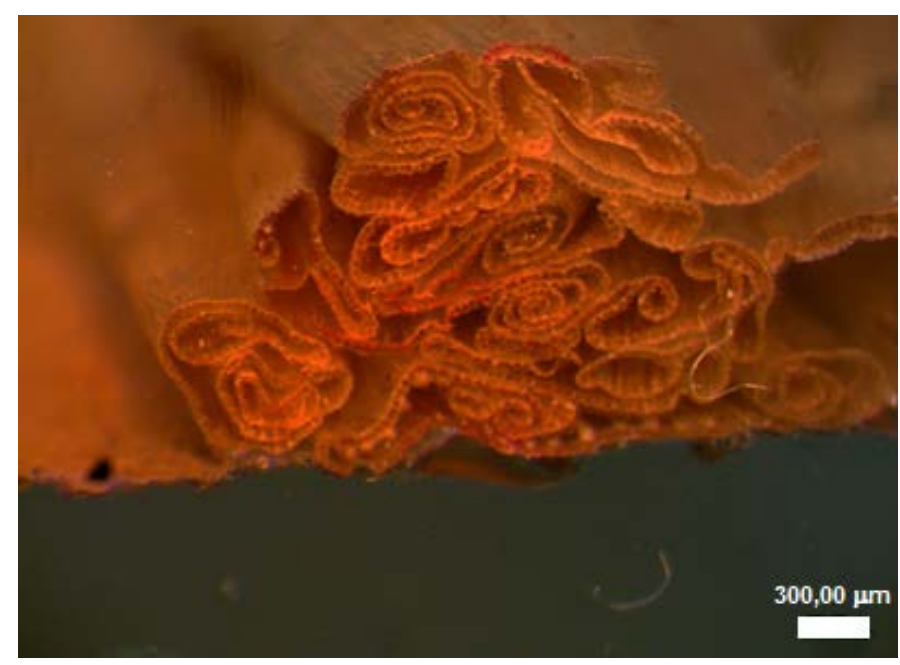

Figura 16: Seção transversal de compósitos reforçados com fibras alinhadas de palha da costa

\section{CONCLUSÕES}

O processo de infusão se mostrou um bom método de fabricação de compósitos reforçados com fibras naturais, pois, além de ser ambientalmente mais favorável por ser um processo de molde fechado, possibilitou a fabricação de produtos com elevado teor de fibra e boas propriedades mecânicas.

O uso do processo de infusão permitiu no melhor caso, a produção de compósitos reforçados com curauá com até 38\% de fração volumétrica de fibras com nível de porosidade abaixo de 3\%; compósitos reforçados com juta com até 32\% de fração volumétrica de fibras com nível de porosidade abaixo de 5\% e compósitos reforçados com palha da costa com até $45 \%$ de fração volumétrica de fibras com nível de porosidade pouco acima de $2 \%$.

O desempenho mecânico em tração dos compósitos reforçados com fibras de curauá alinhadas foi incrementado em 22,2\% e o módulo de elasticidade longitudinal em 48,6\% com a elevação do nível de vácuo de 53,3 para 101,3 kPa principalmente pelo aumento da eficiência da interface fibra/matriz.

Para os níveis mais altos de vácuo, os compósitos reforçados com fios alinhados de juta, em função do elevado diâmetro dos fios, e principalmente da torção superficial das fibras, apresentaram uma redução no seu limite de resistência à tração e rigidez, em função da dificuldade de impregnação do fio pelo poliéster, diminuindo assim o ancoramento mecânico responsável pela transferência de carga da matriz para o reforço.

Os compósitos reforçados com fibras de palha da costa apresentaram o menor desempenho dentre todos os fabricados, em função da menor resistência da fibra em relação às demais e da fraca interface fibramatriz verificada.

\section{AGRADECIMENTOS}

Os autores agradecem à EMBRAPA Amazônia Oriental pelo fornecimento das fibras e ao IFPA, à UFU, à UFOP e à UFPA pelo suporte tecnológico no desenvolvimento do trabalho.

\section{BIBLIOGRAFIA}

[1] FARUK, O., BLEDZKI, A. K., FINK, H. P., SAIN, M., "Biocomposites reinforced with natural fibers: 2000-2010”, Progress in Polymer Science, n. 37, pp. 1552-1596, 2012.

[2] FRANCUCCI, G., RODRIGUEZ, E. S., VÁZQUEZ, A., "Study of saturated and unsaturated permeability in natural fiber fabrics”, Composites: Part A, n. 41, pp. 16-21, 2010.

[3] RAGONDET, A., Experimental characterization of the vacuum infusion process, Tese de D. Sc., University of Nottingham, Nottingham, 2005.

[4] LEVY NETO, F., PARDINI, L. C., Compósitos estruturais: ciência e tecnologia, 1 ed., São Paulo, Edgar Blucher, 2006. 
[5] DHAKAL, H. N., ZHANG, Z. Y., RICHARDSON, M. O. W., "Effect of water absorption on the mechanical properties of hemp fibre reinforced unsaturated polyester composites", Composites Science and Technology, v. 67, pp. 1674-1683, 2007.

[6] MADSEN, B., Properties of plant fibre yarn polymer composites - An experimental study, Tese Danish Ph. D., Technical University of Denmark, Denmark, 2004.

[7] RODRIGUES, J. S., Estudo da técnica de infusão de resina aplicada à fabricação de compósitos de matriz poliéster reforçados por fibras naturais da Amazônia, Tese de D.Sc., Universidade Federal do Pará, Belém, 2014.

[8] SUMMERSCALES, J., DISSANAYAKE, N. P. J., VIRK, A. S., et al., "A review of de bast fibres and their composites. Part 1 - fibres as reinforcements”, Composites: Part A, n. 41, pp. 1329-1335, 2010.

[9] THAKUR, V. K., THAKUR, M. K. "Processing and characterization of natural cellulose fibers/thermoset polymer composites”, Carbohydrate Polymers, n. 109, pp. 102-117, 2014.

[10] JOHN, M. J., THOMAS, S. "Biofibres and Biocomposites”, Carbohydrate Polymers, n. 71, pp. 342364, 2008.

[11] CASARIL, A., GOMES, E. R., SOARES, M. R., et al., “Análise micromecânica dos compósitos com fibras curtas e partículas”, Revista Matéria, v. 12, n. 2, pp. 408-419, 2007.

[12] GOMES, A., MATSUO, T., GODA, K., et al , "Development and effect of alkali treatment on tensile properties of curaua fiber green composites”, Composites: Part A, n. 38, pp. 1811-1820, 2007.

[13] FRANCUCCI, G., RODRÍGUEZ, E. S., VÁSQUEZ, A. "Experimental study of the compaction response of jute fabrics in liquid composite molding processes”, Journal of Composite Materals, n. 46, pp. 155-167, 2011.

[14] SHAH, D. U., SCHUBEL, P. J., CLIFFORD, M. J. "Modelling the effect of yarn twist on the tensile strength of unidirectional plant fibre yarn composites”, Journal of Composite Materials, n. 47, pp. 425-436, 2013.

[15] PORTELA, T. G. R., COSTA, L. L., SANTOS, N. S. S., et al., "Tensile behavior of lignocellulosic fiber reinforced polymer composites: Part II buriti pertiole/polyester”, Revista Matéria, n. 2, pp. 195-201, 2010.

[16] SILVA, R. V., Compósito de Resina Poliuretano Derivada de Óleo de Mamona e Fibras Vegetais, Tese de D. Sc., Universidade de São Paulo, São Paulo, 2003. 